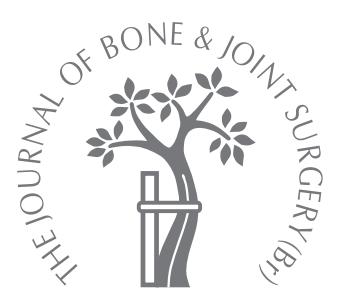

B. D. Sheridan, D. E. Robinson, M. J. W. Hubble, I. G. Winson

From the Avon Orthopaedic Centre, Southmead Hospital, Bristol, England

\title{
Ankle arthrodesis and its relationship to ipsilateral arthritis of the hind- and mid-foot
}

It has been suggested that arthrodesis of the ankle leads to osteoarthritis of the joints of the ipsilateral hind- and midfoot. We believe these studies overlooked the presence of osteoarthritic changes in these joints before the arthrodesis.

We reviewed the pre-operative radiographs of 70 patients with osteoarthritis of the ankle who underwent 71 ankle arthrodeses (one was bilateral). The talonavicular, calcaneocuboid, subtalar and naviculocuneiform joints were given an osteoarthritis score according to Kellgren and Lawrence. The mean age at operation was $\mathbf{5 4 . 9}$ years and the most common indication was for post-traumatic osteoarthritis (52 cases). A total of 68 patients showed pre-existing arthritis in either the hind- or mid-foot, with the subtalar joint the most commonly affected.

Ipsilateral hind- and mid-foot arthritis is almost universally present in patients with arthritis of the ankle requiring arthrodesis. The presence of such changes may not be a consequence of this arthrodesis.

B. D. Sheridan, BSc(Hons), MBChB, MRCS(Ed),

Specialist Registrar, Orthopaedic Surgery Department of Orthopaedic Surgery

Musgrove Park Hospital,

Taunton, Somerset TA1 5DA, UK.

D. E. Robinson, FRCS(Orth), Consultant Orthopaedic Surgeon Royal United Hospital, Coombe Park, Bath BA1 3NG, UK.

M. J. W. Hubble, FRCS(Orth), Consultant Orthopaedic Surgeon Royal Devon and Exeter Hospital, Barrack Road, Exeter EX2 5DW, UK.

I. G. Winson, MBChB, FRCS, Consultant Orthopaedic Surgeon Avon Orthopaedic Centre Southmead Hospital, Westbury-on-Trym, Bristol BS10 5NB, UK.

Correspondence should be sent to Mr B. D. Sheridan; e-mail:

bdsheridan@hotmail.com

(C)2006 British Editorial Society of Bone and Joint Surgery doi:10.1302/0301-620X.88B2. $17065 \$ 2.00$

$J$ Bone Joint Surg [Br] 2006;88-B:206-7.

Received 12 August 2005;

Accepted 20 September 2005
In the younger, active patient the most common indication for arthrodesis of the ankle is post-traumatic arthritis, the risk of which is increased where congruity and the dynamic function are altered. ${ }^{1}$ Arthrodesis may be achieved by open or arthroscopic means, with the latter unable to correct significant deformity.

Although the techniques and implants for ankle arthroplasty have improved this is usually reserved for older patients.

Several long-term studies of arthrodesis of the ankle note an increased incidence of ipsilateral arthritis of the hind- and mid-foot. ${ }^{2-4}$ These degenerative changes are said to be due to altered biomechanics following increased movement to compensate for loss of ankle motion. None of these papers assessed any preexisting arthritis and therefore assume the degenerative changes in the foot are due to the effect of the arthrodesis. We have investigated the degree and pattern of pre-existing ipsilateral arthritis in the foot.

\section{Patients and Methods}

We reviewed the pre-operative radiographs of 70 patients who underwent 71 arthrodeses between 1993 and 2003. There were 43 men and 27 women with a mean age of 54.9 years (27 to 83). The indications for fusion were posttraumatic osteoarthritis (52), primary osteo-
Table I. Radiographic grading of osteoarthritis according to the classification system of Kellgren and Lawrence $^{5}$

\begin{tabular}{ll}
\hline Grade & Description \\
\hline 0 & Normal joint \\
1 & Doubtful osteophytes \\
2 & Definite osteophytes \\
3 & Definite osteophytes and loss of joint space \\
4 & Definite osteophytes, loss of joint space and \\
& deformity \\
\hline
\end{tabular}

arthritis (15), avascular necrosis (2) and infection (2). Patients with inflammatory arthropathy were excluded.

The severity of any osteoarthritis seen in the subtalar, talonavicular, naviculocuneiform and calcaneocuboid joints was graded according to the Kellgren and Lawrence ${ }^{5}$ score (Table I). Measurements were recorded simultaneously by two reviewers (BDS, DER) and a consensus obtained. The maximum scores of four per joint gave a total of 16 points.

The results were assessed using simple statistical analysis of discrete data.

\section{Results}

Of the 71 radiographs, $68(95.8 \%)$ showed pre-existing arthritis in either the hind- or midfoot (Fig. 1). The subtalar joint was the most commonly and severely affected $(77.5 \%)$ (Table 
Table II. Total osteoarthritis score according to the classification of Kellgren and Lawrence ${ }^{5}$ for each joint and the number of times each was affected

\begin{tabular}{lllll}
\hline & Joint & & \\
\cline { 2 - 5 } & Subtalar & Talonavicular & Calcaneocuboid & Naviculocuneiform \\
\hline Total osteoarthritis score & 146 & 96 & 74 & 60 \\
Number of times affected & 63 & 55 & 39 & 36 \\
\hline
\end{tabular}

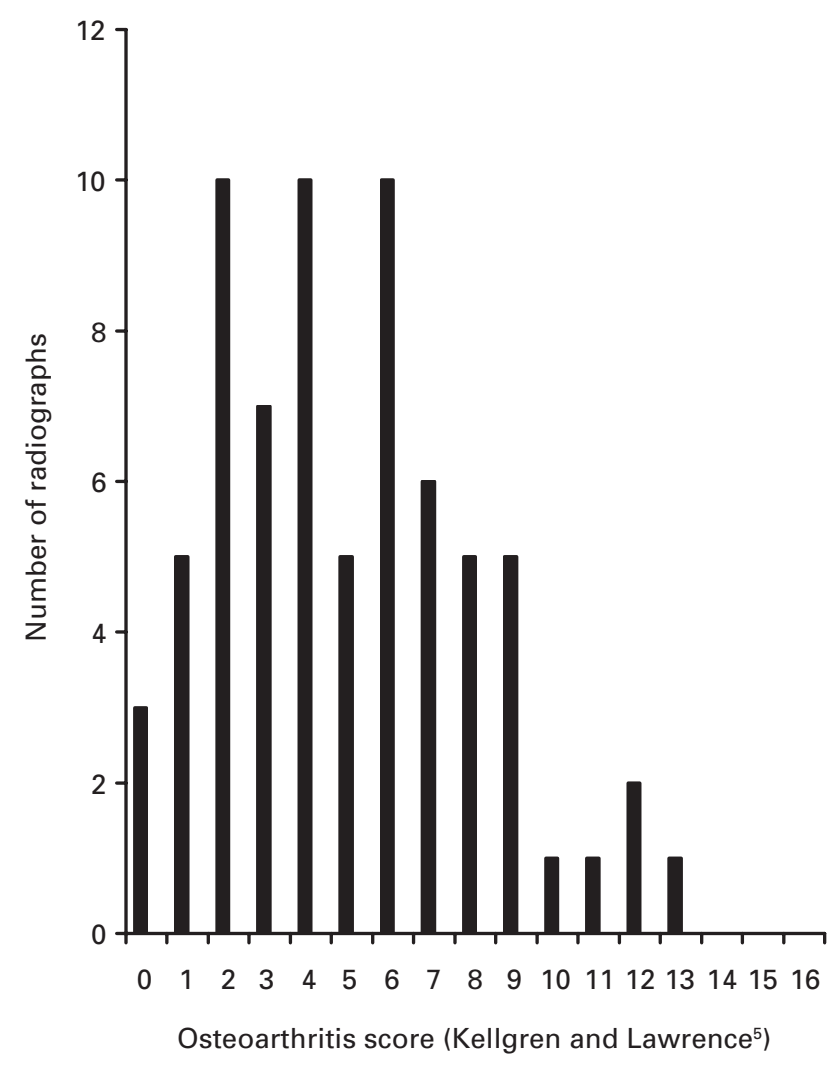

Fig. 1

Bar chart showing the severity of ipsilateral hind- and mid-foot arthritis prior to ankle arthrodesis.

II). The median total arthritis score was 5. There was no association between age or aetiology and the degree of arthritis.

\section{Discussion}

Gait analysis suggests that there is increased ipsilateral movement in the foot after arthrodesis of the ankle. ${ }^{6}$ More recently, radiographic evaluation of tarsal movement following ankle arthrodesis by Abdo and Wasilewski ${ }^{7}$ has not shown significant difference between ipsilateral and contralateral joints. It was felt that tarsal mobility was unaffected by ankle arthrodesis. ${ }^{7}$ This concurs with in vivo movement analysis in normal subjects which shows ranges of movement similar to those in patients with ankle arthro- desis. ${ }^{8}$ If it is accepted that ipsilateral movement in the foot is increased to compensate for a fused ankle, the altered biomechanics could predispose to degenerative arthritis. It is equally possible that, in some cases, the biomechanics are altered before arthrodesis either as a direct result of the developing arthritis in the ankle or secondary to the pathology which caused degeneration of the ankle joint. Alternatively, the so-called excessive movement is not abnormal.

No previous study has identified the degree of pre-operative osteoarthritis. Coester et $\mathrm{al}^{4}$ and Fuchs et $\mathrm{al}^{3}$ highlighted degenerative change in the ipsilateral foot after ankle fusion but stated that nevertheless most patients have a very good long-term outcome and most are happy with their operation.

This study demonstrates that hind- and mid-foot arthritis is very common with coexistent ankle arthritis and that the subtalar joint is usually most severely affected. Coester et $\mathrm{al}^{4}$ and Fuchs et $\mathrm{al}^{3}$ described a similar picture as an effect of arthrodesis. They assumed this followed the surgery, but equally it could have been present pre-operatively. This possibility therefore needs to be considered when evaluating the results of arthrodesis of the ankle. It cannot be stated that ipsilateral arthritis in the foot is an absolute long-term effect of arthrodesis, as it may be predetermined and multifactorial.

A prospective study, serially assessing radiographic and clinical changes in a population pre- and post-ankle arthrodesis might provide further evidence supporting this possibility.

No benefits in any form have been received or will be received from a commercial party related directly or indirectly to the subject of this article.

\section{References}

1. Thomas RH, Daniels TR. Ankle arthritis. J Bone Joint Surg [Am]2003;85-A:923-36.

2. Takakura $\mathbf{Y}$, Tanaka $\mathbf{Y}$, Sugimoto $\mathrm{K}$, Akiyama $\mathrm{K}$, Tamai S. Long-term results of arthrodesis for osteoarthritis of the ankle. Clin Orthop 1999;361:178-85.

3. Fuchs S, Sandmann A, Skwar A, Chylarecki C. Quality of life 20 years after arthrodesis of the ankle: a study of adjacent joints. J Bone Joint Surg [Br] 2003;85-B: 994-8.

4. Coester LM, Saltzman CL, Leupold J, Pontarelli W. Long-term results following ankle arthrodesis for post-traumatic arthritis. J Bone Joint Surg [Am] 2001;83-A: 219-28.

5. Kellgren J, Lawrence J. Radiological assessment of osteo-arthrosis. Ann Rheum Dis 1957;16:494-502.

6. Mazur JM, Schwartz E, Simon SR. Ankle arthrodesis: long-term follow up with gait analysis. J Bone Joint Surg [Am]1979;61-A:964-75.

7. Abdo RV, Wasilewski SA. Ankle arthrodesis: a long-term study. Foot Ankle 1992; 13:307-12.

8. Winson IG, Lundberg A, Bylund C. The pattern of motion in the longitudinal arch of the foot. Foot 1994:4:151-4. 